\title{
Android/IOS Based Electric Wheelchair
}

Shalizan Kadir, Benny Azmi Mohd Zamlan, Syahlan Abd Halim, Haidie Inun, Caroline Dame Siagian

To Link this Article: http://dx.doi.org/10.6007/IJARBSS/v11-i6/10117 DOI:10.6007/IJARBSS/v11-i6/10117

Received: 11 April 2021, Revised: 14 May 2021, Accepted: 30 May 2021

Published Online: 09 June 2021

In-Text Citation: (Kadir et al., 2021)

To Cite this Article: Kadir, S., Zamlan, B. A. M., Halim, S. A., Inun, H., \& Siagian, C. D. (2021). Android/IOS Based Electric Wheelchair. International Journal of Academic Research in Business and Social Sciences, 11(6), 268-275.

\section{Copyright: (c) 2021 The Author(s)}

Published by Human Resource Management Academic Research Society (www.hrmars.com)

This article is published under the Creative Commons Attribution (CC BY 4.0) license. Anyone may reproduce, distribute, translate and create derivative works of this article (for both commercial and non-commercial purposes), subject to full attribution to the original publication and authors. The full terms of this license may be seen at: http://creativecommons.org/licences/by/4.0/legalcode

Vol. 11, No. 6, 2021, Pg. 268 - 275

Full Terms \& Conditions of access and use can be found at http://hrmars.com/index.php/pages/detail/publication-ethics 


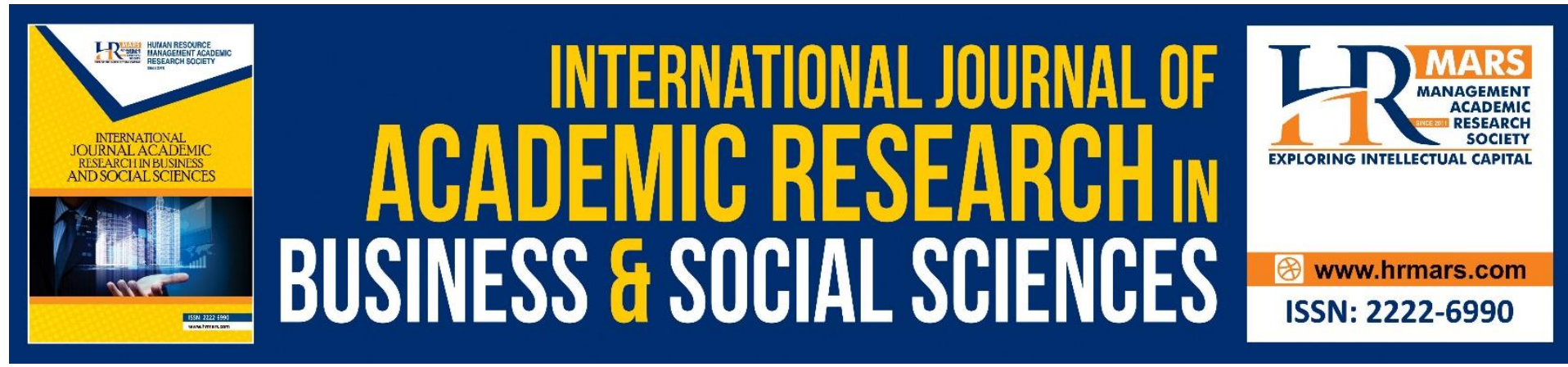

\title{
Android/IOS Based Electric Wheelchair
}

\author{
Shalizan Kadir, Benny Azmi Mohd Zamlan, Syahlan Abd Halim, \\ Haidie Inun, Caroline Dame Siagian \\ Politeknik Kota Kinabalu Malaysia
}

\begin{abstract}
This project proposes control of Electric Wheelchairs by using smartphones to help the movement of the disabled and the elderly become easier. Although the use of manual wheelchairs can meet the needs of some individuals there are also some who have problems using these manual wheelchairs due to some factor such as permanent disability in the hands and in the case of senior citizens, the lack of energy to move the wheelchair manually. As we all know, mobile phones are a necessity nowadays, with almost everyone having them. By combining smartphone and Bluetooth technology, this manual wheelchair can be converted to Electric wheelchair that can be controlled wirelessly using a smartphone and therefore solve the problem mentioned above since it is easy to move the wheelchair around without requiring too much energy. This project uses an Arduino as the main controller to control the DC motor that is attached to the wheelchair. Several versions of smartphone apps have been developed to make sure it's achieved its objective. In conclusion, this project will be able to help those in need to move more easily and independently.
\end{abstract}

Keywords: Smartphone, Electric Wheelchair, Android, IOS, Arduino.

\section{Introduction}

The popular type of manual wheelchair now is a pushing type wheelchair which requires the user to move the wheel by hand or with the help of someone to push the wheelchair from the rear. Although this method has been used and proven to be effective, there are several wheelchair users who have trouble moving the wheelchair themselves due to the inability of the hand to move the wheel. This is because to move this wheelchair requires quite a lot of energy especially if you want to move far and fast. Furthermore, caregivers who help push these wheelchairs are also having trouble pushing the wheelchair due to several factors such as age and physical weakness. This makes it even more difficult for disability people to move around. To overcome this problem, we propose an Electrical Wheelchair, a type of power wheelchair which can be moved by electrical power. Users can control the movement of this wheelchair by simply using the app on a smartphone that is connected to the Dc motor installed on the wheelchair via Bluetooth technology. Main controller for this system is using an Arduino mega. This paper will focus on the development of the smartphone apps and design system. 


\section{Problem Statement \& Objective}

The use of wheelchairs is intended to facilitate the movement of people with disabilities. However, the continuous use of manual wheelchairs for a long time is very tiring not only for the wheelchair users but also for the caregivers who help push and move the wheelchair. This will make it difficult for people with disabilities to move, especially in case of emergencies that require immediate movement and action.

Considering all these factors, this study suggests a new system called "Android/IOS Electric Wheelchair" where this manual wheelchair can be moved using electric power and its movement can be controlled by using a smartphone. This new system will use electricity to move the wheelchair and solve the problem of using manpower to move the wheelchair.

This study embarks on the following objectives:

1) To reduce the workload of manpower to push and move the manual wheelchair by replacing it with electrical power.

2) To control the movement of the wheelchair by using smartphone apps.

3) To develop smartphone app

\section{Related Work}

Several studies have been carried out such as controlling the wheelchair using voicerecognition systems (Rakhi et al., 2016). Similar concept has been applied by another researcher by using human voice as input to move the wheelchair (Apsana, Renjitha, 2016). Both of these systems use speech recognition technology where users can control the movement of the wheelchair just by voice, based on the command that has been set. Although this is a good technology, there are weaknesses in terms of input (voice command) accuracy especially in relatively noisy areas. The system might not detect the voice command or misinterpreted it.

Another project related to wheelchair technology uses the concept of motion detection as input (Rakhi et al., 2013; Vishal \& Prashanth, 2016). This system uses gesture recognition so a handicap person who cannot make use of his hands can drive a chair by head movements. Although it uses the latest technology, one of its disadvantages is its relatively expensive cost.

A recent study proposes an android mobile-based wheelchair controller is used. The system is designed to control a wheelchair by using an android device like mobile (Balsaraf et al., 2017) Based on all this research, we propose the system with a slight improvement by converting standard manual wheelchair to electric wheelchair and using a user-friendly mobile app that is easy to use without neglecting the safety factor.

\section{Propose System}

The main hardware of this system consists of microcontroller Arduino Mega as main controller. The smartphone will be used as an input. A set of instructions will be sent using the smartphone application to the Arduino board via wireless connection using Bluetooth technology. This set of instructions will then be processed by the Arduino control board which in turn will control the movement of the DC motor. This in turn allows the user to move the wheelchair in the desired direction of movement as an output. 




Figure 1. Block Diagram of propose Electric Wheelchair

\section{Hardware Requirement}

The main hardware consists of a system that is based on an Arduino MEGA board, Motor Driver, 24V DC motor, Bluetooth Module HC-05, and a Smartphone. The smartphone can be in android or iOS platform. To power up the motor, a pack of batteries with $24 \mathrm{~V}, 14.4 \mathrm{Ah}$ capacity are required and $450 \mathrm{~W}$ power needed for motors.

\section{Software Requirement}

There are two main software used in this project:

1. The android/iOS application is built using Massachusetts Institute of Technology (MIT) App Inventor, an open system online visual programming.

2. Arduino compiler

\section{Model Design}

This Electric Wheelchair design idea considers the comfort and cost that consumers must bear. Therefore, for this purpose this design Electric Wheelchair prototype is made by modifying the existing manual wheelchair on the market whose size is standard size and comfortable for most users. By simply modifying the existing manual wheelchairs, it can also reduce costs compared to making special electric wheelchairs from scratch. To convert a manual wheelchair to an electric wheelchair, two 24V DC motors are mounted on both sides of the wheelchair tires which are connected using chains. The box which contains the controller circuit and battery pack will be placed behind the wheelchair to facilitate battery replacement, battery charging and even circuit maintenance in the event of a malfunction and these control boxes can be easily opened and installed. 


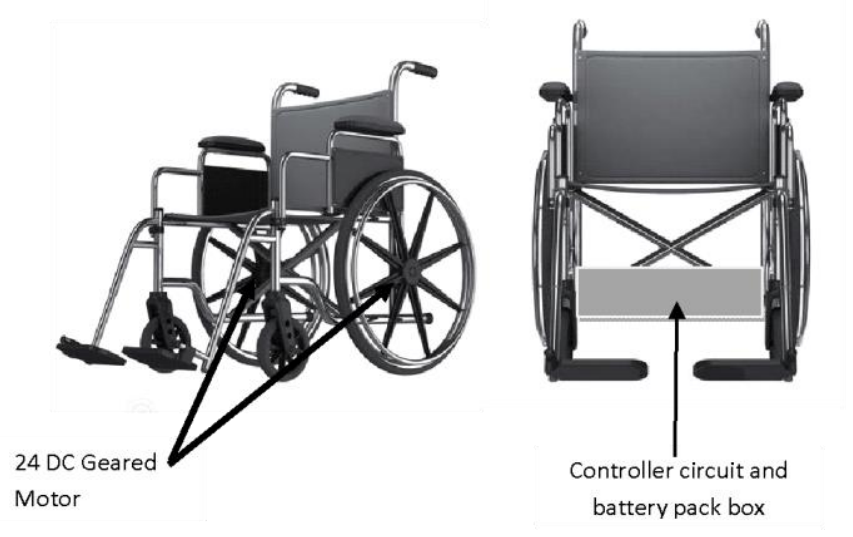

Figure 2. Model Design of Electric Wheelchair

By default, there are 4 main operations that can be controlled by this electric wheelchair user. The operations are as following:

1. Moving Forward

2. Moving Backward

3. Turning to the Right

4. Turning to the left

This wheelchair movement will stop automatically if no input or operation is received through the smartphone application.

\section{Result \& Discussion}

Figure 3 shows a prototype wheelchair that has been developed. Figure 3 (a) shows the side view of the wheelchair where the DC motor and chain are mounted on the wheelchair. This installation is permanent and cannot be moved. However, it does not interfere with the physical structure of the wheelchair and it can still be folded. Figure 3 (b) shows the position of the control circuit box that houses the circuit as well as the battery pack to control the movement of the motor. While Figure 3 (c) shows a control box that can be easily opened for the purpose of circuit inspection or battery replacement. The installation of this circuit control box is not permanent and is easy to open and reinstall.

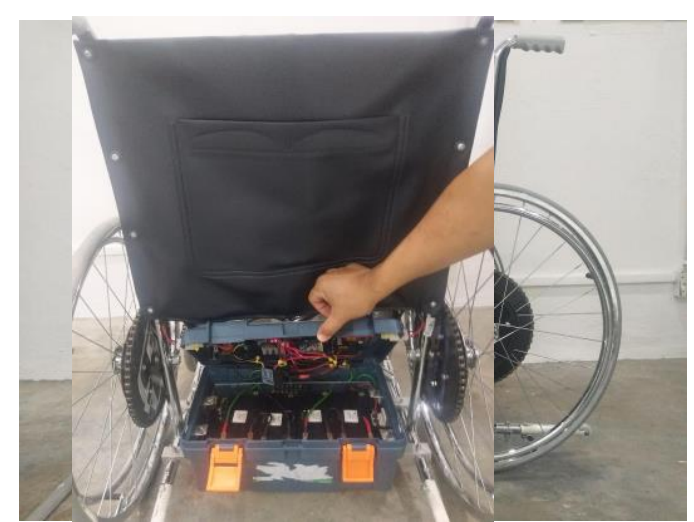

(a)

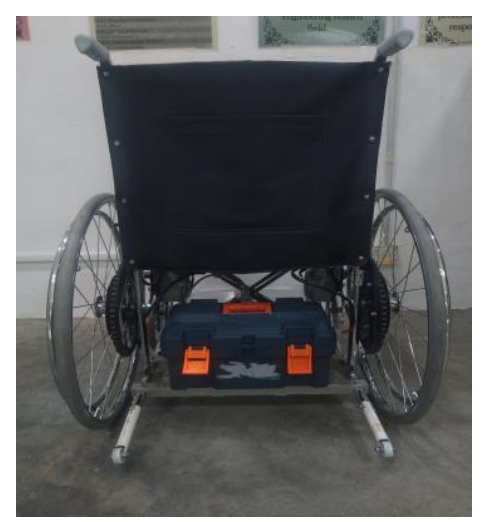

(b)

(c) 


\section{Figure 3. Prototype of Electric Wheelchair}

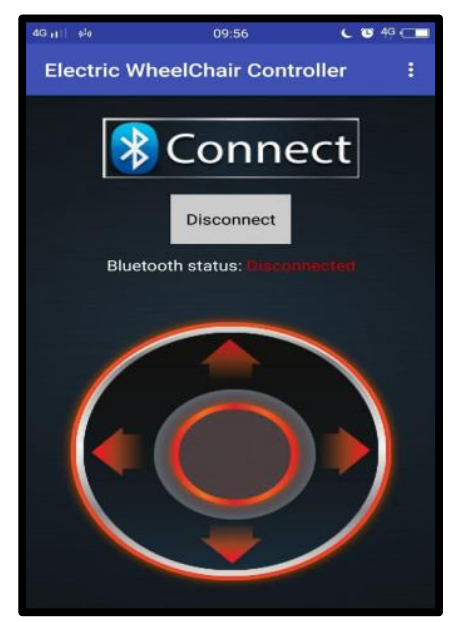

Figure 4. Graphic User Interface for mobile app

Figure 4 shows the Graphic User Interface for a smartphone application used to control the movement of a wheelchair. This is the second version of the development of this smartphone control application. The first version only allows regular movement in 4 directions, while for the second version there are improvements in terms of movement control by adding a control button in the middle where the user can freely control the joystick movement, compared to previous version where the direction only limited to 4 movements according to the direction of the arrow. Bluetooth connectivity needs to be done first, and the status of this connection will be visible on the application interface view. However, this is not the final version as there are still some related issues such as unstable connection and there are a few errors when the user moves the wheelchair.

Figure 5 shows a test session controlling this wheelchair using a smartphone application that has been developed. Physically, this electric wheelchair has no problems moving according to the instruction and can carry loads up to $100 \mathrm{~kg}$. However, there are still issues with the stability of smartphone applications as already mentioned.

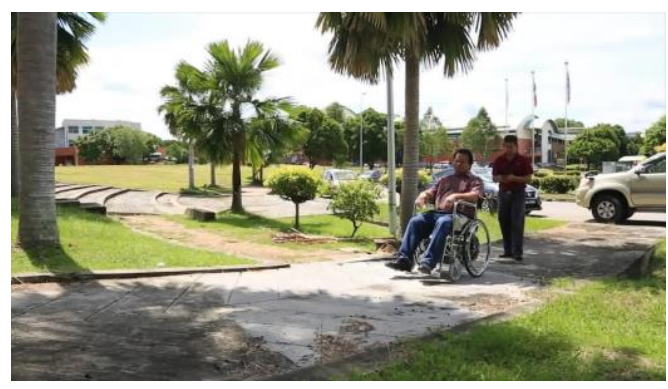

(a)

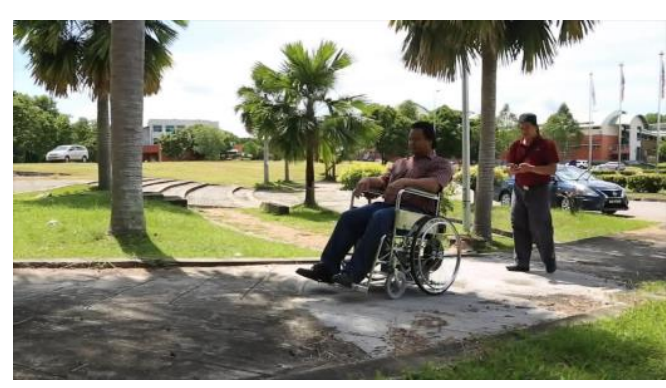

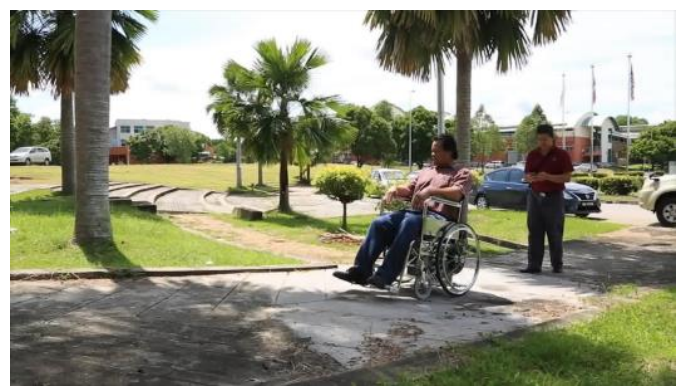

(b)

(d)

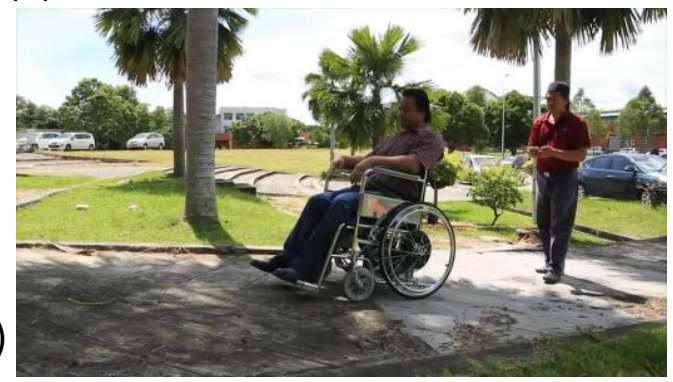




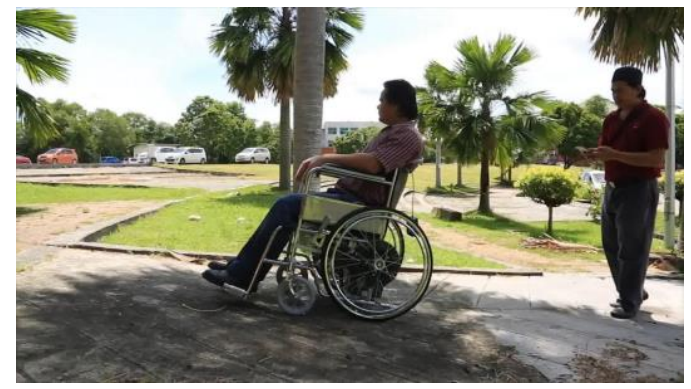

(e)

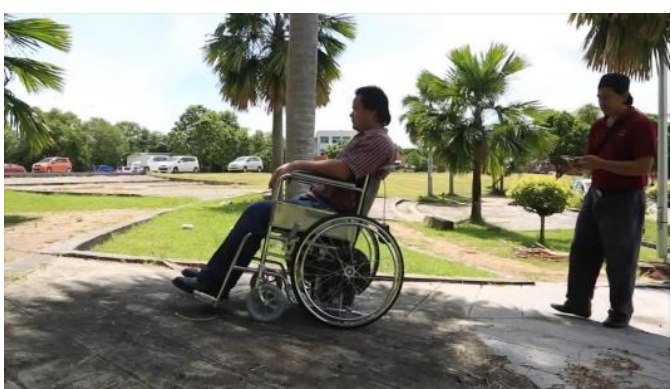

(f)

Figure 5. Electric Wheelchair testing sessions using a smartphone app

\section{Advantage}

This proposed electric wheelchair uses simple and easy-to-use technology. The cost used is also relatively cheap compared to specially ordered electric wheelchairs since we just modify the standard wheelchair. The components used are also available in the market and do not need to be specially ordered, thus facilitating maintenance and repair in the event of damage.

\section{Future Scope of Project}

For further improvement, the following are some suggestions:

1. To resolves smartphone app instability issues

2. To add alternative control methods such as joystick or voice control system.

3. To add ultrasonic sensor at the back of the wheelchair to detect objects or obstacles when moving backward

\section{Conclusion}

This proposed system will not only help people with disabilities to move more easily but also can help caregivers to help push and move wheelchairs without using a lot of energy. However, there is still room for improvement and further study needs to be done given its relatively wide potential for use.

\section{Corresponding Author}

Shalizan bin Kadir, Politeknik Kota Kinabalu, Malaysia

No. 4, Jalan Politeknik, KKIP Barat, Kota Kinabalu Industrial Park, Politeknik Kota Kinabalu, 88460 Kota Kinabalu, Sabah.

Email: shalizan@polikk.edu.my

\section{References}

Bhardwaj, R., Gupta, P., Jadhav, P., Kadam, B., \& Kedari, A. (2016). Android-based automated smart wheelchair. International Journal of Innovative Research in Computer and Communication Engineering, 4(3), 3040-3047.

Jamuna, R., Kumar, K.B. \& Karthikeyan, P. (2015). Wheelchair control using voice recognition.International Journal of Advanced Research in Biology, Ecology,Science and Technology,1(1), 13-16.

Leandre Nsengumuremyi, Aman Jung Karki, Manjunath CR. (2018) "Smart Wheelchair using Medical IOT" International Journal for Research in Applied Science \& Engineering Technology (IJRASET) ,6,387-393 
Lodhi, D. K., Vats, P., Varun, A., Solanki, P., Gupta, R., Pandey, M. K., \& Butola, R. (2016). Smart electronic wheelchair using arduino and bluetooth module. International Journal of Computer Science and Mobile Computing, 5(5), 433-438

Rakhi, A. K., \& Chitre, D. K. (2013). Automatic wheelchair using gesture recognition, International Journal of Engineering and Innovative Technology (IJEIT), 2(9), 216-218. Vishal, V. P., Nikita, S. U., Darshana, P. M., Nikita, R. I., \& Pragati, P. M. (2014). Hand Gesture Based Wheelchair Movement Control for Disabled Person Using MEMS. Journal of Engineering Research and Applications, 4(4), 152-158. 